\title{
OBJETIVISMO Y SUBJETIVISMO EN LA FILOSOFÍA DE LOS VALORES
}

Francisco Miró Quesada C.

UNIVERSIDAD DE LIMA

\section{Planteamiento del problema}

Una de las maneras más usuales de fundamentar la ética es recurrir al concepto de valor. Según esta posición una acción es ética cuando su finalidad es la realización de algún valor que ocupa una posición determinada en relación con otros valores. Hay una escala de valores y la acción ética será tanto más apreciable cuanto más alto sea el valor que intenta realizar. La conciencia moral consiste en darse cuenta de que hay determinada escala de valores y que el individuo tiene la exigencia de realizarse como persona de acuerdo con sus respectivas jerarquías.

La concepción axiológica de la ética permite describir y explicar las acciones morales de manera directa, y de todos los intentos por fundamentar la moral es el que presenta mayor espontaneidad y mayor carácter intuitivo. Sin embargo, cuando es sometida a un análisis ceñido se descubren dificultades teóricas muy grandes. De un lado, se ve que el concepto de valor no es nada claro y que es difícil determinar sus rasgos distintivos. De otro lado, se presenta el problema de saber si los valores son objetivos, independientes de la conciencia individual que los capta o si, por el contrario, no son sino entidades dependientes del sujeto que valora.

En lo que sigue vamos a analizar, primero, los problemas que se presentan cuando se analiza el concepto de valor y luego abordaremos las dificultades, en nuestro concepto insobrepasables, que presenta el intento de fundamentar la ética recurriendo al concepto de valor, tanto en su versión objetivista como subjetivista. Hecho esto, trataremos de mostrar que hay una manera de fundamentar la ética que está libre de las dificultades que se presentan cuando se adopta cualquiera de las anteriores posiciones.

\section{El concepto de valor}

Lo primero que se ve cuando se comienza a analizar el concepto de valor es que existen diferentes tipos de valores: valores económicos, valo- 
res biológicos, valores estéticos, valores éticos o morales. En lo que sigue concentramos el análisis en los valores éticos, pues lo que nos interesa es el problema que presenta el intento de fundamentar la ética. ${ }^{1}$

Aunque los valores éticos pueden presentar muchas variaciones y modalidades, creemos que todas ellas pueden agruparse en dos grandes clases: valores entitativos y valores racionales. Los primeros son los valores de las personas individuales y de las entidades colectivas como la familia, la patria, la humanidad. ${ }^{2}$ Los segundos son los valores de las conductas individuales, es decir, de la manera como los individuos se relacionan entre sí. ${ }^{3}$

Cuando se consideran los valores entitativos se presenta la dificultad de saber de qué manera se relaciona la persona (o entidad colectiva) con el valor. A primera vista se tiene la impresión de que el valor coincide con la persona. En efecto, la persona humana, por el mero hecho de ser, vale. Por lo menos para otras personas que pueden considerarse como humanistas. Desgraciadamente, los "antihumanistas" abundan y su huella sangrienta a través de la historia es una estela de ferocidad y destrucción. Más adelante veremos que el antihumanismo está relacionado, de manera consciente o inconsciente, con determinada filosofía de los valores. Ambas posiciones significan que toda persona en cuanto tal debe realizarse plenamente, porque una característica esencial del valor es que exige su realización. Pero si se identifica a la persona con su valor, quiere decir que el valor personal es algo concreto, que está en el tiempo y en el espacio, puesto que es la misma persona. En consecuencia, el valor personal nace, crece, se reproduce y muere. Decir de un valor que experimenta las vicisitudes de las personas parece raro. Sin embargo, si se identifica el valor de la persona con la propia

1 Es un hecho que los diferentes tipos de valores están relacionados entre sí. Por ejemplo, hay oposiciones y concordancias entre los valores morales, los económicos y los estéticos. Mas para la comprensión del presente texto no es necesario analizar estas interrelaciones.

Aunque algunos autores diferencian entre el significado de "ética" y "moral", nosotros, basándonos en razones etimológicas, empleamos dichas palabras como sinónimos. Asimismo, utilizamos como sinónimos las palabras "cultura" y "civilización", a pesar de que sus etimologias son diferentes.

2 Al hablar de valores de entidades colectivas no hacemos ningún supuesto metafísico que constituya una hipóstasis de dichas entidades. La expresión "entidad colectiva" se remite a algo que está integrado por individuos que se relacionan entre sí de cierta manera. Que este algo sea más que dichas relaciones individuales o que se reduzca a ellas es un problema que no es necesario abordar para la comprensión del presente texto. Basta reconocer que hay entidades como la familia, la patria, etc., que, cuando se mencionan, son claramente reconocibles y que estos entes no pueden constituirse sin la existencia de relaciones entre determinados conjuntos de individuos.

3 El comportamiento de las entidades colectivas es difícil de analizar. De manera general puede decirse que este comportamiento sólo puede producirse por medio del comportamiento de sus integrantes individuales. Pero el hecho de que el comportamiento de estos integrantes presente ciertas regularidades permite considerar que el comportamiento es de la entidad colectiva que integran. 
persona se trata de una consecuencia inevitable. Porque es precisamente por eso que la persona se nos presenta intangible. Dañar a la persona es atentar contra un valor. La exigencia de respetar la vida y la integridad física y psicológica de la persona se explica, precisamente, porque la persona, considerada como un todo concreto, es un valor.

Pero, por otra parte, vemos que cuando una persona muere, sigue valiendo. Los grandes personajes históricos, los sabios, los santos, los forjadores del destino de un pueblo, son considerados valiosos a través de la historia. Pero no sólo las grandes personalidades. Una persona puede tener un profundo significado para un grupo, ser considerado como un valor permanente a pesar de que ha desaparecido. Mas si el valor de una persona es la persona misma, la permanencia en el tiempo cuando la persona ya ha desaparecido no se comprende bien. La única manera de comprender esta permanencia es distinguir entre el valor de la persona y el valor de la persona como protagonista de conductas. Es un hecho patente que unas personas son consideradas más valiosas que otras y que el origen de esta diferencia de valor está en la conducta. Los grandes personajes históricos son personajes que han tenido conductas extraordinarias. Estas conductas son consideradas valiosas y el valor que se les atribuye confiere valor a las personas que las protagonizaron.

De acuerdo con lo dicho, el valor de la persona no sería algo simple sino que constaría de dos componentes. Un componente es el valor que toda persona tiene por el mero hecho de ser persona. Este componente es el mismo en todos los seres humanos (por lo menos para la concepción humanista de la ética). Otro componente es el resultado de la conducta de la persona a través de su vida; es este segundo componente el que confiere a las personas mayor o menor jerarquía valorativa. Ciertas conductas elevan el valor de la persona a niveles extraordinarios, mientras que otras lo rebajan de manera pavorosa. Y esto plantea el problema de la relación entre el valor de la persona y el valor de la persona como protagonista de conductas.

De un lado, se tiene la impresión de que se trata de dos componentes independientes, porque el componente general, es decir, el valor de la persona en cuanto persona puede no existir en determinadas culturas; en cambio, el componente conductual parece ser una constante a través de la historia. El valor intrínseco de la persona parece ser una creación de la civilización occidental cuyo origen se halla, probablemente, en el cristianismo. Pero en muchas civilizaciones este valor parece hallarse ausente, el individuo como tal parece no tener un valor en sí mismo y sólo adquiere valor mediante su conducta. ${ }^{4}$ Sin embargo, el valor de la conducta depende de una relación entre personas. La conducta de una persona se considera valiosa porque

4 Es difícil saber si el valor intrínseco de la persona humana está totalmente ausente en determinadas culturas. Pero es obvio que en algunas parece no existir conciencia de su reconocimiento; por ejemplo, en las civilizaciones esclavistas. 
realiza algo en favor de otras personas. De manera que, en último término, el valor de la conducta parece derivarse del valor de las personas. Por ejemplo, el valor de la conducta generosa se debe a que el que se comporta generosamente se desprende de bienes para darlos a otras personas. $Y$ esto significa que las personas favorecidas son consideradas valiosas. Si no fuera así la generosidad no tendría ningún significado ético.

Hay, como vemos, una situación ambigua respecto del valor de las personas en cuanto personas. En ciertas culturas las personas no parecen ser consideradas como valores intrínsecos y sólo parecen tener valor (o desvalor) mediante sus conductas. Pero la conducta es considerada valiosa porque está referida a personas. De manera que las personas son consideradas valiosas en sí mismas. Posiblemente esta valoración no es, por lo general, plenamente consciente. Tal vez la civilización occidental es la única que toma conciencia de la relación del valor de la conducta con el valor intrínseco de las personas. ${ }^{5}$ Posiblemente esta toma de conciencia se produce con el cristianismo. En el cristianismo auténtico el valor de la conducta reside en la manera como el protagonista reconoce el valor de las demás personas. El amor es considerado el valor supremo porque en el amor la persona amada es reconocida en la plenitud de su valor.

Una situación análoga se presenta cuando en lugar del valor de las personas individuales se considera el valor de las entidades colectivas como la ciudad, la patria, la humanidad. El valor de la persona se juzga por la manera como se comporta respecto de estas entidades. Y ello muestra que se considera que estas entidades son valiosas en sí mismas. Por otra parte, también se puede considerar el valor de la conducta de ciertas entidades colectivas, como la familia o un grupo determinado. En este caso la situación es aún más compleja. Pero en esencia es la misma; la conducta es considerada valiosa porque hace algo en favor de personas o entidades que son, a su vez, consideradas valiosas de manera directa o indirecta.

5 En algunas culturas como la hindú, la islámica y la china, hay manifestaciones superiores de la filosofía y de la religión en las que se reconoce el valor intrínseco de la persona humana. Pero no puede decirse que este reconocimiento sea una vigencia cultural, cosa que sí puede decirse de la civilización occidental. Además, en el budismo la actitud que asume alguien ante las demás personas no se debe a que las aprecie o que las ame, sino a que, adoptando dicha actitud, va a progresar en el difícil proceso de liberación frente a la rueda de la vida y acercarse a la meta final que es la disolución de la individualidad en el nirvana. En el budismo no hay calor humano. Lo mismo puede decirse del brahamanismo, cuya meta final es la experiencia del gran todo en que todo es uno y uno es todo. Esta actitud induce a considerar con gran indiferencia el sufrimiento humano. La tesis del velo de Maya es reveladora en este respecto.

Es cierto que en las civilizaciones china e hindú hay concepciones metafísicas y éticas para todos los gustos. Hay sistemas éticos que pueden ser considerados humanistas, pero estos sistemas nunca lograron tener una influencia importante. En lenguaje orteguiano, nunca llegaron a tener vigencia. En cambio el cristianismo llegó a tener vigencia casi universal en la sociedad europea. 
Así, el valor intrínseco parecería ser el valor fundamental puesto que el valor de las conductas sólo tiene sentido en relación con las personas. Sin embargo, cuando se piensa sobre el origen del valor intrínseco de las personas se ve que reside en el hecho de que las personas son capaces de asumir conductas valiosas. Un recién nacido es apreciado como un valor intangible porque, conforme vaya desarrollando su personalidad, irá siendo cada vez más capaz de asumir conductas valiosas. El valor de la persona es prospectivo, está referido a sus acciones posibles de manera que, en última instancia, depende del valor de su comportamiento. Pero, como hemos visto, el valor del comportamiento de una persona sólo tiene sentido porque está referido a las personas que son objeto de dicho comportamiento.

De acuerdo con lo dicho, creemos que el significado de la palabra "valor" es ambiguo. Cuando se dice de una persona que es valiosa la expresión puede referirse al valor intrínseco de dicha persona o a su valor como protagonista de conductas. Pero la ambigüedad de "valor" se presenta, asimismo, cuando se mencionan los valores en general. Por ejemplo, cuando se habla del valor de la generosidad, o de la lealtad, no se ve con claridad qué es lo que se está mencionando. Si se quiere definir, o mejor, describir, el valor de la lealtad, se tiene que hacer referencia a la conducta leal. El valor de la lealtad es el valor que tiene una conducta que es veraz, que es fiel, que proporciona ayuda cuando se requiere, que jamás traiciona, etc. No parece, pues, existir el valor de la lealtad en sí mismo: sólo existe el valor de las conductas leales. Mas, por otra parte, una conducta leal es valiosa porque realiza el valor de la lealtad. El lenguaje común es, en este respecto, como el filosófico: la palabra "valor" se remite directamente a un objeto. Cuando se emplean expresiones como el "valor del heroísmo", "el valor de la sabiduría", etc., se entienden perfectamente de manera preanalítica. Pero cuando se analizan, se remiten inevitablemente a las conductas valiosas. Y cuando se analiza el significado de expresiones como "conducta leal", "conducta patriótica", etc., dichas conductas resultan valiosas porque realizan el valor de la lealtad, el valor del patriotismo, etc. Hay así una circularidad entre el significado de "valor" y "conducta valiosa". De un lado, el valor de la lealtad parece ser algo distinto de la conducta leal; de otro lado, cuando se trata de precisar qué se entiende por dicho valor, se tiene que recurrir a la conducta leal. Y lo mismo en los demás casos.

Los análisis efectuados permiten evitar, así lo creemos, malentendidos cuando se utiliza la palabra "valor" en algún contexto. Sobre todo, hacen posible emplear dicha palabra para expresar ideas, formular problemas y señalar vías de exploración sin peligro de confusión. 
Consideraciones generales sobre el objetivismo y el subjetivismo en relación con los valores

Las tesis objetivista y subjetivista respecto de los valores pueden concebirse de diversas maneras. Creemos que la mejor manera de plantearlas es respondiendo a las siguientes preguntas: ¿un comportamiento es valioso porque un individuo o varios individuos (por ejemplo, una comunidad determinada) lo aprueban, o lo aprueban porque es valioso? O también: ¿una persona (o entidad colectiva) vale porque es considerada valiosa, o es considerada valiosa porque vale? Si se sostiene que un comportamiento es valioso porque es aprobado, o que una persona vale porque es considerada valiosa, se adopta la posición subjetivista. Si se sostiene que un comportamiento se aprueba porque es valioso, o que una persona es considerada valiosa porque vale, se adopta la posición objetivista.

La discusión sobre la objetividad o la subjetividad de los valores es casi tan antigua como la misma filosofía. Desde el enfrentamiento de Sócrates y Platón con los sofistas hasta nuestros días se ha discutido sobre el tema en forma permanente y, a veces, con dramático apasionamiento. De manera general puede decirse que los argumentos objetivistas son de dos tipos. Un primer tipo consiste en mostrar que hay valores que se imponen a través de la historia y que esta permanencia sólo puede explicarse si se considera que dichos valores son objetivos. Un segundo tipo es que si los valores no fueran objetivos, entonces todo estaría permitido. Llamamos a este argumento -que a pesar de que lógica y epistemológicamente no tiene mayor asidero, es sumamente fuerte- el argumento del todo vale. Los argumentos subjetivistas consisten, principalmente, en encontrar contraejemplos frente a los ejemplos objetivistas. Así, si un objetivista sostiene que determinado tipo de conducta o de entidad es considerado valioso a través de la historia, el subjetivista tratará de encontrar un caso en que sea considerado desvalioso.

Para justificar su posición el objetivista puede proceder de dos maneras. La primera consiste en encontrar el origen del valor en un hecho que trasciende las conductas y las personas (o entidades colectivas). La segunda consiste en encontrar este origen en la propia conducta individual o en las personas (y en las entidades colectivas).

En el primer tipo de justificación el origen del valor puede ser la existencia de un ser divino. La manera como el valor se relaciona con este ser supremo depende de la posición filosófica que se adopte. Así, para un intelectualista como Santo Tomás, lo que hace que los valores valgan es la naturaleza divina. Lo bueno y lo malo no pueden variar porque, para ello, tendría que variar la naturaleza divina. Para un voluntarista, como San Pedro Damián, la voluntad de Dios puede hacer que lo que hoy es aprobable mañana sea repudiable. 
Pero este primer tipo de justificación puede hacerse prescindiendo de Dios. Algunos filósofos sostienen que la moral es un producto de la evolución y que sus normas más fundamentales son imprescindibles para la conservación y perpetuación de la especie. El origen de la moral y, en consecuencia de los valores, se halla en el código genético (Wilson).

En el segundo tipo de justificación el objetivista sostiene que ciertas acciones deben ser aprobadas (o exigidas o reprobadas) o que las personas individuales o colectivas son consideradas valiosas simplemente porque dichas acciones o dichas personas son valiosas en sí mismas, con total independencia de los procesos psicológicos mediante los cuales se captan (Scheler, Hartmann). O sea, los comportamientos y las personas valen porque valen y su valor se impone a las conciencias individuales. Esta concepción se asemeja a la del racionalista que considera que ciertos principios lógicos o ciertas verdades matemáticas se imponen a la conciencia por medio de la evidencia intelectual. No pueden probarse porque no es necesario probarlos ya que su verdad es aprehendida de manera directa. Para algunos filósofos de la ética, como Moore, la evidencia con que se captan los valores es intelectual. Para otros, como Scheler y Hartmann, la evidencia no es intelectual sino emocional. En cuanto al argumento del todo vale, como hemos dicho, no tiene asidero teórico, pero tiene un poder suasorio muy grande, especialmente para los que hemos interiorizado los criterios morales de la civilización occidental. Sea cual sea la razón por la que reaccionamos ante el argumento del todo vale, el hecho es que este argumento permite dar ejemplos que nos son absolutamente insoportables. El siguiente ejemplo, tomado de Ernesto Garzón Valdez, es una muestra impresionante de la fuerza del todo vale. El jurista nazi Karl Larenz, en un texto publicado cuando el Tercer Reich estaba en la plenitud de su poderío, dice lo siguiente:

El juez está obligado a reconocer y aplicar toda ley que entre en vigencia por la voluntad del Führer; pero tiene que aplicarla por la voluntad del Führer...

El objetivista, mediante ejemplos como éste, muestra que hay conductas que nos parecen tan indignas que no pueden aceptarse éticamente. Y la única manera de explicar este hecho es que tanto los valores como los desvalores son objetivos. Karl Larenz y todos los que pensaban como él padecían de ceguera axiológica, o tal vez mejor, de daltonismo axiológico. Este hecho en la esfera moral puede compararse con el del esquizofrénico que no reconoce los principios lógicos o los capta deformados. Pero la respuesta del subjetivista es muy fuerte. La ceguera o el daltonismo axiológico se pueden presentar en unos cuantos individuos, pero no pueden darse en todo un pueblo. Y no podemos olvidar que posiciones como la de Karl Larenz fueron aprobadas por casi la totalidad de ochenta millones de alemanes. No podemos negar que se trata de un excelente contraejemplo. 
Mas los subjetivistas no sólo recurren a contraejemplos para refutar a los objetivistas, también tratan de explicar el hecho de que existen comportamientos y personas considerados valiosos, recurriendo al origen del valor. No vamos a analizar las diferentes posiciones pues no es ésta la intención del presente trabajo. Bástenos decir que para unos el origen del valor es el sentimiento (Perry, 1926); para otros es la emoción (Russell, 1949, 1977; Ayer, 1936); para Nietzsche son creaciones de la voluntad de poderío o del miedo del débil y del esclavo (1906).

Una posición difícil de ubicar es la del historicismo. Si los valores dependen de la estructura y del dinamismo de la sociedad en una etapa determinada de su historia, entonces puede pensarse que no dependen de la conciencia de los individuos. El individuo, conforme desarrolla y va tomando conciencia de sí mismo, va encontrando valores que no dependen de su voluntad y que para él son objetivos. El historicismo vendría a ser así una especie de relativismo objetivista. Sin embargo, si se analiza la manera como los valores van cambiando a través de la historia, se descubre que los cambios se deben a que ciertos individuos y grupos cambian, en algún momento, sus criterios valorativos. Si este cambio es subjetivo, su difusión consiste en que los demás individuos del grupo, por influencia de los primeros, vayan, también, cambiando sus criterios anteriores. En este sentido el historicismo axiológico sería, obviamente, un subjetivismo. Pero si se conciben los cambios como algo causado por mecanismos objetivos, por ejemplo, por la contradicción existente entre las fuerzas de producción y las relaciones de producción, como sostienen los marxistas, entonces se trata de un objetivismo relativista. Es objetivismo porque el cambio en los criterios valorativos depende del modo de producción, a determinado modo corresponde cierta manera de valorar conductas y personas, y no puede corresponder otro. Esta doble posibilidad de concebir el historicismo muestra que aunque todo subjetivismo ético es un relativismo, no todo relativismo es un subjetivismo.

\section{Crítica del objetivismo y del subjetivismo}

Los subjetivistas pretenden que tanto la aprobación (o desaprobación) de las conductas como la valoración (positiva o negativa) de las personas depende de las actitudes que asumen los individuos. Y para probar su tesis recurren, como hemos dicho, a ejemplos que muestran que principios morales considerados universales o por ciertas personas o grupos son desconocidos o rechazados por otras personas y grupos. En la aplicación de esta metodologia se puede avanzar bastante lejos. No cabe duda de que en muchísimos casos se pueden encontrar contraejemplos de criterios de valoración que son considerados universales por determinados individuos, grupos e incluso colectividades. Por ejemplo, un valor que parece tan arraigado co- 
mo la patria es considerado por los marxistas clásicos como un componente de la ideología de la clase dominante que es muy útil para lograr que dicha clase se perpetúe en el poder. Un desvalor tan grande, en diversas culturas, como el incesto, no lo es en ciertas sociedades en que pueden casarse entre hermanos (el faraón debía casarse con su hermana; el inca podía casarse con su hermana). La revolución sexual de los últimos tiempos muestra cláramente cómo ciertos valores que eran considerados sacrosantos en la época victoriana, hoy día son considerados ridículas ñoñerías. La moderna figura del hurto famélico muestra cómo el robo, que en la sóciedad aristocrática era considerado punible en todos los casos, es visto en nuestros días, cuando es auténtico, como un hecho que no merece castigo. Otro hecho impresionante es la diferencia entre las sociedades totalitarias y democráticas en las que se encuentran criterios de valoración radicalmente distintos; en las primeras, estos criterios dependen de la voluntad del líder o de la cúpula partidaria; mientras que en las segundas una cantidad muy grande de criterios valorativos consisten en la consulta de la voluntad popular.

A esto replican los objetivistas que hay valores como la lealtad, el heroísmo, el espíritu de sacrificio, la generosidad, la veracidad, etc., que se encuentran en todas las épocas. Por más que busquemos no podremos encontrar una sociedad en la que la lealtad sea desaprobada y la deslealtad aprobada. ${ }^{6}$

La respuesta del subjetivista es que valores como la lealtad, el heroísmo, etc., son valores conductuales y que estos valores sólo son reconocidos cuando las conductas están referidas a personas valiosas. Asi, ser leal a un hombre noble es considerado valioso, pero ser leal a un gangster es juzgado negativamente.

Sin embargo, la situación no es clara pues la lealtad, aunque sea de un gangster, tiene, siempre, algo de valioso. Un pistolero que se deja torturar y matar con tal de salvar la vida de su jefe no deja de producir cierta admiración. Y la traición, aunque sea a un gangster, produce, siempre, reacciones negativas. El delator nunca es considerado una persona valiosa. Puede ser útil en un caso determinado, pero en sí mismo es valorado negativamente. La frase de Calderón de la Barca: "El traidor no es menester siendo la traición pasada" lo dice todo.

Pero el subjetivista insite en que valores como la lealtad, el heroísmo, etc., a pesar de su aparente estabilidad, son en último término variables.

6 Podría pensarse que algunos de los valores mencionados no se conocen en ciertas culturas o en ciertas etapas de una misma cultura. Por ejemplo, durante el Renacimiento parecería que el valor de la lealtad no fuera reconocido por nadie. Sin embargo, una cosa es que una amplia proporción de la conducta política se caracterizara por su falta de lealtad y otra que el valor de la lealtad no fuera apreciado. Basta enterarse de la manera como se formaban los grupos políticos y las alianzas durante el Renacimiento, para darse cuenta de que la lealtad era apreciada, incluso por los más desleales, cuando se trataba de reclutar partidarios. 
Aunque es cierto que, por lo general, son considerados positivamente, hay casos en que las personas (o grupos o colectividades) tienen un valor tan negativo que el valor conductual asociado con ellos pierde toda posible positividad. Por ejemplo, en el caso de la invasión de un país por otro, el que colabora con el invasor es un traidor y como tal su persona es considerada un desvalor. Si un colaborador es leal al invasor esa lealtad no hace sino que los del país invadido lo consideren traidor en máximo grado.

Las consideraciones que anteceden muestran que ni el objetivismo ni el subjetivismo pueden mantenerse de manera convincente. El subjetivismo, cuando se trata de fundamentar la ética por medio de valores, tiene mayor asidero. Su método del contraejemplo puede aplicarse en un número muy grande de casos. Estos casos han aumentado considerablemente con los descubrimientos de la antropología y de la etnohistoria, que revelan que hay sociedades en las que existen criterios de valor que, comparados con los occidentales, producen una incómoda impresión de extrañeza.

Sin embargo, el subjetivismo presenta dificultades. Si bien es cierto que el valor de la persona en cuanto persona no es una invariante histórica, hay valores de entidades colectivas que parecen ser invariantes o sufrir sólo fluctuaciones que no signifiquen que tienen carácter subjetivo. El valor de la patria es uno de ellos. En todas las épocas la patria ha sido un valor fundamental. Incluso en una sociedad tan diferente de todas las demás como la espartana, en la que todos los valores parecían haberse invertido, la patria era considerada el valor supremo. Y, a pesar de que, según el marxismo, la patria no es sino un recurso burgués para movilizar a las masas proletarias a su favor, en la Unión Soviética, una vez instalado el régimen comunista, tuvieron que reconocer su vigencia y reconocieron el valor de la patria socialista. Es cierto que en la actualidad grupos cada vez más numerosos consideran que el valor de la humanidad ocupa un cargo más alto que el de la patria, pero en ningún momento se ha negado el valor de la patria. Lo que se sostiene es que en nombre de la patria no deben realizarse acciones que atenten contra la humanidad. Pero ello no significa que la patria no deba ser amada y defendida con la vida si es necesario.

En conclusión, podemos decir lo siguiente. Aunque el subjetivismo lleva la mejor parte en la polémica, no logra explicar la innegable constancia de ciertos valores a través de la historia y no es, por eso, convincente. Es cierto que estos valores no son absolutamente invariantes como son, por ejemplo, ciertas verdades lógicas y matemáticas; ${ }^{7}$ pero el hecho es que, con algunas

7 Es sabido que en relación con los principios lógicos y matemáticos hay posiciones contrapuestas. Pero lo que importa señalar es que, una vez que se aceptan dichos principios, su verdad no es una consecuencia del consenso sino que el consenso es una consecuencia del hecho de que su verdad es captada como algo evidente por quienes la aceptan. El tema de la intuición intelectual y de la evidencia de los principios lógicos y matemáticos es sumamente complejo y rebasa el ámbito del presente ensayo. Pero lo que es claro es que dichos principios 
fluctuaciones, aparecen y reaparecen en las más diversas circunstancias históricas. La impresión que se tiene, por eso, es que ni el subjetivismo ni el objetivismo son capaces de ofrecer una visión aceptable de la manera como se relacionan los individuos y las colectividades con los valores, ni logran presentar una comprensión adecuada de la vida moral.

\section{Dificultades intrínsecas de una ética de los valores}

Las dificultades que hemos señalado muestran que el intento de fundamentar una ética recurriendo a los valores presenta dificultades insuperables. De un lado, el objetivismo es incapaz de explicar la variación de los valores a través de la historia, variación que, en ciertos casos, adquiere aspectos inverosímiles. Por otro lado, el subjetivismo no puede explicar el hecho de la constancia con que aparecen ciertos valores y, lo que es decisivo en todo intento de fundamentar una ética, es incapaz de responder al argumento del todo vale.

Creemos que cuando se recurre a los valores para fundamentar la ética, el objetivismo y subjetivismo son las dos únicas maneras de hacer la fundamentación. Los intentos por superar estas posiciones dentro de un marco axiológico caen dentro de una $u$ otra; por ejemplo, el intento de Frondizi de superar la dicotomía, considerando el valor como una cualidad estructural. Según Frondizi, si el valor fuera subjetivo sería como las cualidades descriptivas secundarias (color, sabor, etc.). Pero el valor no es una cualidad secundaria, ni siquiera, primaria. No es de ninguna manera un complejo de cualidades descriptivas. El valor es una cualidad estructural. Esto significa que la situación en que el sujeto valora, que es objetiva, forma parte del valor y lo condiciona (Frondizi, 1978, p. 547). El subjetivismo está errado, según Frondizi, porque sólo presta atención a las reacciones del individuo pero la situación es transubjetiva. El objetivismo se equivoca porque la situación es empírica y afecta el valor, lo que contraría el apriorismo absolutista que lo caracteriza (Frondizi, 1978, p. 545).

Pero si los valores varían con la situación, se recae en el subjetivismo. En efecto, Frondizi nos dice que los valores morales en la guerra y en la paz son distintos (Frondizi, 1978, p. 548). Pero de lo que se trata es, precisamente, de que sean los mismos. Si no fueran los mismos, nunca podría considerarse la guerra como un desvalor. Se cae, así, en un relativismo que impide fundamentar la ética. Porque lo que hoy parece un valor supremo debido a que estamos en una situación determinada, mañana puede parecer

no pueden utilizarse sin que se presuponga su validez universal. Una posición puramente convencionalista respecto de ellos es insostenible. Quienes niegan la universalidad de determinados principios se fundan, para hacer esto, en principios cuya evidencia es reconocida explícita o implícitamente (sobre este punto, véase Miró Quesada, "Crítica de la razón impura", en J. Camacho (comp.), La racionalidad, IIH, Lima, 1988, pp. 13-29). 
un desvalor inaceptable, simplemente, porque ha cambiado la situación. En esta forma sería imposible mantener una ética de los derechos humanos. Por otra parte, el concepto de situación es ambiguo y difícil de analizar. ¿De qué situación se habla, en efecto? ¿De una situación colectiva o de una situación individual? Si es de una situación colectiva, entonces hay que deslindar con claridad lo que ella significa en relación con los diferentes grupos humanos. Por ejemplo, ¿cuál es la situación del hombre europeo en la Europa de la segunda mitad del siglo XIX? ¿Tienen los proletarios la misma situación que los burgueses? Si la tienen, entonces los valores de ambas clases deben ser los mismos. Pero lo cierto es que la situación de ambas clases es diferente. $Y$ esto hace imposible saber cuál es la ética que debe seguirse. En realidad, las situaciones sociales e históricas son sumamente complejas. Dentro de cada situación hay diferentes situaciones y dentro de cada una de éstas se encuentran muchas otras que varían al infinito. ¿Cuál es la situación que debe tomarse como base para determinar la tabla de valores sobre la que se fundamenta la ética?

Vemos, por lo que antecede, que el intento de fundamentar la ética sobre los valores conduce a callejones sin salida. El objetivismo no puede resistir los contraejemplos que muestran excepciones respecto de las normas consideradas universales; el subjetivismo no puede explicar ciertas invariancias a través de la historia y, además, conduce a un relativismo inaceptable. $Y$ una posición como la de Frondizi, que constituye, a no dudarlo, un esfuerzo brillante, nos conduce, sin embargo, al mismo relativismo.

Para que el objetivismo pudiera aceptarse debería haber un sistema de valores de vigencia suprahistórica, es decir, una tabla de valores jerarquizados que fuera independiente de las situaciones históricas y de las preferencias psicológicas. $Y$ un sistema que cumpla estas condiciones no existe. Hay algunos valores como los que hemos mencionado (lealtad, heroísmo, generosidad, etc.) que tienen cierta permanencia histórica. Pero decimos "cierta permanencia" porque no se trata de una invariancia total. Como hemos visto, los valores que parecen tener permanencia histórica son relacionales y son afectados por los valores personales. Y esto les imprime cambios de posición en la escala jerárquica. Por eso, lo más que puede decirse sobre dichos valores es que se presentan en las diferentes civilizaciones y en diferentes épocas de la misma civilización, pero que, en ambos casos, pueden presentar variaciones. No encontramos, por eso, una tabla jerarquizada de valores que pueda considerarse verdaderamente invariante.

Pero este hecho tampoco constituye un argumento decisivo en favor del subjetivismo. Porque, a pesar de las variaciones que experimentan las tablas de valores, el hecho de que ciertos valores relacionales se encuentren en las más diversas culturas y en diversas épocas de la misma cultura muestra que no pueden reducirse a meras preferencias de los sujetos. Si así fuera, podría haber civilizaciones en que valores como los mencionados no se presenta- 
ran. Pero hay algo así como una terquedad valorativa, una tendencia a que ciertos valores sean permanentes. Y esta tendencia se manifiesta, incluso, en relación con ciertos valores entitativos como, por ejemplo, la patria.

La situación es, en verdad, desconcertante. El sólido edificio exigido por el objetivismo se derrumba ante la evidencia histórica y antropológica. Pero al derrumbarse, no se cae todo el edificio, quedan vestigios, determinadas estructuras permanecen a través de las épocas. Mas, dentro de ciertas formas muy generales, sufren, a su vez, alteraciones que impiden considerar que se trata de una invariancia relativa. En pocas palabras, el panorama axiológico no es suficientemente nítido para que pueda aprovecharse en favor del objetivismo y no es suficientemente borroso para que pueda utilizarse de manera contundente como una prueba del subjetivismo.

Sobre la posibilidad de una fundamentación racional de la ética

El hecho de que no se pueda fundamentar la ética sobre los valores no significa que una fundamentación de la ética sea imposible. Creemos que si, en lugar de utilizar criterios valorativos, se utiliza un criterio de racionalidad, el problema de la fundamentación de la ética se puede abordar con mayores probabilidades de éxito.

El primero en haber intentado una fundamentación racional de la ética ha sido Kant. ${ }^{8}$ Conocidos son sus argumentos en contra de una ética basada en principios prácticos materiales en los que incluye los sentimientos morales (en lenguaje moderno esto significa la exclusión de una ética de valores). Conocida es también su tesis de que una fundamentación racional de la ética sólo puede establecerse sobre la base de la universalidad. En nuestra opinión, ambas posiciones son correctas y con ellas Kant inaugura una nueva etapa en la historia de la ética. Pero la manera como Kant aplica el criterio de la universalidad en la fundamentación de la ética está plagada de dificultades y, además, subrepticiamente reintroduce el concepto del valor al considerar la razón como un valor supremo (Kant 66, pp. 46, 91, 92). Entrar en el análisis de estas dificultades sería demasiado largo. Por eso, en lo que sigue, vamos a seguir nuestro propio pensamiento sin hacer referencia a la concepción kantiana. El lector juzgará por sí mismo hasta dónde somos deudores de Kant y hasta dónde hemos podido avanzar por nuestro propio camino.

El criterio de racionalidad se puede enunciar como sigue: una conducta es éticamente aceptable si el fin que persigue es racional. El enunciado del

8 Como siempre, en el caso de la fundamentación racional de la ética hay antecedentes. Platón y los estoicos fueron los primeros en intentar esta fundamentación y, en la filosofía moderna, los jusnaturalistas y Spinoza. Sin embargo creemos que Kant fue el primero que comprendió a fondo que esta fundamentación no podía ser metafísica, como creían Platón, los estoicos y el mismo Spinoza, y el primero que trató de llevarla hasta las últimas consecuencias. 
criterio nos hace ver que no se considera el término racional en sentido instrumental. La racionalidad instrumental, en efecto, está referida a los medios y no a los fines. Un medio para alcanzar un fin es racional si permite alcanzarlo de manera eficaz. El concepto de eficacia presenta algunos aspectos huidizos al análisis pero, en principio, puede considerarse que un medio es eficaz para alcanzar un fin si es optimal, es decir, si permite alcanzar dicho fin con la mayor rapidez y el menor gasto de recursos y de energía posibles. Desde luego, una persona puede tratar de alcanzar un fin utilizando ciertos medios porque ignora la posibilidad de utilizar otros más eficaces, de manera que en el concepto de racionalidad instrumental intervienen elementos epistémicos. Por eso, la eficacia es relativa a los recursos disponibles y al grado de información que se posee. Pero, de manera general, puede determinarse con relativa facilidad si los medios empleados para alcanzar un fin son o no adecuados.

Cuando se trata de fines racionales es evidente que la racionalidad no consiste en ninguna eficacia. Para aclarar el sentido de la expresión es conveniente analizar el significado del término racional. Este término tiene innumerables acepciones y en cada una de ellas descubrimos delicados matices que son difíciles de precișar. Pero una nota que se encuentra en todas las acepciones es la aceptabilidad universal. Así, si un conocimiento es racional (está racionalmente fundado) debe ser un conocimiento aceptado por todos. Esta aceptabilidad es una nota constitutiva del concepto de racionalidad. Es contradictorio decir que un concomiento es racional pero que no es aceptable por todos. El hecho de que para ciertas personas una proposición constituye un conocimiento racionalmente fundado mientras que para otras la misma proposición no es un conocimiento porque es falsa muestra que, en ciertas circunstancias, puede ser difícil ponerse de acuerdo sobre la racionalidad de un conocimiento. Si no fuere así, no habría historia de la filosofía. Pero lo importante es darse cuenta de que la nota de universalidad es una nota constitutiva del concepto de racionalidad. Puede haber discrepancias entre los sujetos $A$ y $B$ sobre la racionalidad de un conocimiento, pero si $A$ cree que la verdad de la proposición " $p$ " está racionalmente establecida, está convencido de que dicha verdad es igual para todos los sujetos cognoscentes. Que el sujeto $B$ no acepte la verdad de " $p$ " significa para $A$ que $B$ está equivocado y que hay algún aspecto en el proceso de la fundamentación racional de la verdad de " $p$ " que ha escapado a la atención de $B$. Recíprocamente, $B$ considera que la verdad de " $p$ " no está racionalmente fundada pues si lo estuviera, " $p$ " sería verdadera y su verdad debería ser reconocida por todos.

Un hecho que confirma lo que decimos es la actitud del escéptico. El escéptico no cree que haya conocimientos universalmente válidos porque no cree que el conocimiento se puede fundar racionalmente. Si creyese lo contrario tendría que aceptar que hay conocimientos universales. Otro he- 
cho es que la racionalidad instrumental supone, asimismo, la universalidad. Si un medio para alcanzar un fin es racional, entonces es un medio aceptable por todo aquel que quiera alcanzar el mismo fin.

Ahora bien, cuando se trata de conocimientos o de medios (en relación con los recursos disponibles), la universalidad es obvia: consiste en la aceptabilidad general. Esto permite pensar que cuando se trata de los fines se puede aplicar el mismo criterio: un fin es racional cuando es universalmente aceptable. Pero de inmediato surge una dificultad. En el caso del conocimiento y en el caso de los medios (en relación con los recursos disponibles), la universalidad se impone a la conciencia individual. Si un conocimiento está racionalmente fundado todos tienen que aceptar que es verdadero; si un medio es idóneo para realizar un fin, nadie puede decir que no lo es. Pero cuando se trata de fines la situación es muy diferente. La persecución de un fin significa que se quiere realizar determinado valor y ya hemos visto que no hay criterios objetivos de valoración o, que si los hay, son escasos y nunca pueden ser aplicados con plena seguridad. Si los valores son subjetivos, entonces no hay ningún criterio que permita saber cuándo un fin es universalmente aceptable. La única manera de lograr esta universalidad sería que existiesen criterios objetivos nítidamente destacables. Mas, como hemos visto, estos criterios no existen.

Sin embargo, aunque la universalidad de un fin no puede establecerse de la misma manera como se establece la universalidad de un conocimiento o la eficacia de un medio, hay una manera de establecerla: por consenso. Si toda la comunidad se pone de acuerdo sobre la realización de un fin, no cabe duda de que dicho fin será universalmente aceptable. Será aceptable por el simple hecho de que ha sido aceptado. Y, si es así, tendrá una de las notas constitutivas de la racionalidad.

\section{Condiciones necesarias y suficientes de racionalidad}

Hemos visto que la universalidad es una nota constitutiva de la racionalidad, pero no es la única. Cuando se analiza, por ejemplo, lo que constituye la racionalidad de un conocimiento, se ve que se trata de un proceso complicado y que presenta diferentes aspectos. Uno de ellos es la universalidad. Pero la universalidad no es lo que permite la constitución racional del conocimiento. Para que un conocimiento sea racionalmente fundado deben cumplirse determinadas condiciones. Por ejemplo, si se trata de un conocimiento matemático debe haberse constituido mediante evidencias intelectuales, o mediante procesos deductivos, a veces muy complicados, cuyas premisas iniciales $y / o$ cuyas reglas de inferencia son evidentes o se aceptan por estipulación (hay que recordar lo dicho en la nota 7). Si se trata de un conocimiento empírico, por ejemplo, una teoría física, su fundamentación racional exige la corroboración empírica de las consecuencias deductivas de 
las hipótesis fundamentales, etc. Si se procede de esta manera, entonces los conocimientos adquiridos tienen validez universal. La universalidad viene a ser, así, una consecuencia del proceso mediante el cual se fundamenta racionalmente el conocimiento. Lo mismo sucede cuando se trata de la racionalidad de los medios, racionalidad que, en último término, viene a ser una racionalidad cognoscitiva. Esto muestra que la universalidad, aunque es una nota constitutiva de la racionalidad, es una condición necesaria pero no suficiente de la misma. Es decir, algo no puede ser racional si no es universalmente aceptable, pero no basta que sea universalmente aceptable para que sea racional. Hubo una época en que la creencia de que la Tierra era plana era universal y, obviamente, era universalmente aceptable puesto que todos la aceptaban y, sin embargo, dicha creencia no era un conocimiento racionalmente fundado puesto que era errónea.

Si en lugar del conocimiento consideramos la conducta, vemos que la situación es como sigue. La universalidad como condición necesaria de racionalidad se aplica de la misma manera. Una conducta que persigue un fin que no es universalmente aceptable no puede ser racional. Pero no basta que el fin perseguido sea universalmente aceptable para que pueda ser considerado racional. Cuando nos situamos en la dimensión de la ética, esta relación entre universalidad y racionalidad se ve con especial claridad. Así, el racismo como norma ética no es racional puesto que no es universalmente aceptable (es evidente que ningún individuo perteneciente a las razas consideradas inferiores por el racista aceptaría la norma). Pero una norma que estableciera que todos los días al levantarse hay que señalar con el brazo derecho al norte es perfectamente universalizable y, sin embargo, no tiene ninguna significación ética.

La dificultad que se encuentra cuando se quiere fundamentar racionalmente la ética es que cuando se trata de fines no parece que existan criterios suficientes de racionalidad. Por más esfuerzos que se hagan no puede saberse, como sucede en el caso del conocimiento y de la racionalidad instrumental, cuáles son las condiciones que deben cumplirse para que un fin sea considerado racional. Sólo sabemos que si un fin no es universalmente aceptable no puede ser racional y, en consecuencia, no puede ser ético. Pero tratar de encontrar condiciones suficientes de racionalidad, como hacen los objetivistas, es recaer en el callejón sin salida de la ética axiológica.

\section{Más allá del objetivismo y del subjetivismo}

El criterio de universalidad no permite establecer condiciones suficientes de eticidad. Y esto muestra que, por sí sólo, no puede ofrecer una fundamentación completa de la ética. Toda ética, para ser tal, requiere de contenidos materiales, es decir, de una tabla jerarquizada de valores. Estas tablas varían a través de la historia y aunque, como hemos visto, en algunos aspectos pre- 
sentan ciertas constantes, consideradas como sistemas sufren con el tiempo alteraciones que hacen imposible considerarlas objetivas. Sin embargo, son estas tablas las que hacen posibles la vida moral.

Pero el criterio de universalidad, si bien no ofrece condiciones suficientes de eticidad, permite efectuar un control respecto de los diferentes sistemas éticos. Porque si las normas éticas de un sistema moral, en una situación histórica determinada, no son universalizables, no cumplen el requisito de racionalidad y si no cumplen este requisito no son éticamente aceptables. La aplicación del criterio de universalidad realiza algo así como una poda del sistema moral al que se aplica. Es fácil ver que la poda deja mucho en pie, pues muchas de las normas que integran el sistema moral analizado son universalizables. Por ejemplo, es obvio que el matrimonio por rapto, como existía en tiempos primitivos, no es universalizable, pero sí lo es el matrimonio exogámico, que es la forma que prevalece en la mayor parte de las sociedades históricas. Y muchas exigencias éticas en diferentes civilizaciones, como la veracidad, la lealtad, la generosidad, la honradez, son perfectamente universalizables.

El criterio de universalidad, como expresión de la concepción racional de la ética es, así, compatible con una ética material de los valores. Pero sólo lo es parcialmente. Dado un sistema de normas éticas, si se aplica el criterio de universalidad, quedan eliminadas las normas que prescriben (o permiten) conductas que no son universalizables, pero permanecen todas las demás. Muchas de estas normas pueden parecer sin sentido ético a un observador que las ve desde fuera del sistema. Pero si son universalizables son racionalmente admisibles. Por ejemplo, cierto tipo de ceremonias que se celebran para establecer la validez de determinadas relaciones humanas, como el matrimonio o el paso de la pubertad a la adultez, etc. Aunque para un miembro de otra cultura se trate de actos que no significan nada para él, si decidiese vivir en la cultura en que dichos actos se celebran podría aceptar sin dificultad celebrarlos de acuerdo con lo exigido por las normas. En cambio serían inaceptables para él normas que exigieran sacrificios humanos o que permitieran la venta de esclavos.

Una objeción que puede hacerse a la fundamentación racional de la ética, tal como la hemos concebido, es que no logra superar el subjetivismo. Porque el hecho de haber elegido la racionalidad como fundamento de la ética supone una elección y toda elección es subjetiva. Cuando se trata del conocimiento la racionalidad se impone por sí misma. El conocimiento se funda racionalmente utilizando ciertos principios no porque el sujeto cognoscente los elige, sino porque ellos se imponen con evidencia. Nuestra propia razón nos impone la necesidad de utilizarlos. Pero la decisión de adoptar una ética racional, es decir, que sólo permita conductas cuyos fines son racionales, no es la consecuencia de un proceso racional. No puede demostrarse racionalmente que debemos ser racionales. Por eso, el hecho de 
elegir una ética racional presupone que la racionalidad es, para nosotros, un valor fundamental. Al tratar de evitar el subjetivismo mediante la fundamentación racional de la ética, recaemos, así, en la posición que se quiere evitar.

Esta objeción es correcta. Es cierto que, en último término, la elección de una ética racionalmente fundada se basa en un valoración y, en consecuencia, en un proceso emocional. Sin embargo, paradojicamente, una vez que se elige fundamentar la ética racionalmente, las dificultades que surgen cuando se adopta la posición subjetivista o la objetivista desaparecen.

El hecho desconcertante para el subjetivista de que hay valores que reaparecen en todas las civilizaciones y en diferentes etapas de una misma civilización es perfectamente compatible con la posición racionalista. Si la conducta orientada por dichos valores no es universalizable no es éticamente aceptable; si, en cambio, es universalizable, debe ser aceptada. Es muy interesante percatarse de que los valores que mantienen una invariancia, aunque sea relativa, a través de la historia, son fácilmente universalizables (la lealtad, el heroísmo, la generosidad, la veracidad, etc.). Esto permitiría pensar que en diferentes etapas de la historia y en diversas civilizaciones, de manera no plenamente consciente, se ha aplicado el criterio de racionalidad. En todo caso, el hecho es que sea cual sea el fundamento que se haya propuesto para considerar ciertos comportamientos éticos, en el caso de los valores mencionados se puede aplicar dicho criterio.

Asimismo, con la adopción del criterio de racionalidad desaparece la demoledora objeción del todo vale. No todo vale puesto que no pueden admitirse conductas que no sean universalizables.

Las dificultades del objetivismo también son superadas. En efecto, es cierto que los valores y las normas de conducta cambian a través de la historia. Pero si una conducta es universalizable es éticamente aceptable aunque en un momento dado de la historia ya no se practique. En los sistemas de moral que se han sucedido a través del tiempo, podemos distinguir las conductas y los valores universalizables y su aceptación ética será independiente de su variación o de su permanencia. Hay conductas y valores que se han mantenido largo tiempo y han pasado de una civilización a otra y que, sin embargo, no son aceptables éticamente porque no son universalizables. Si se adopta el criterio de la racionalidad, como vemos, desaparece la dificultad insuperable del objetivismo: si los valores fueran objetivos no deberían sufrir variaciones históricas.

Sin embargo, a pesar de que, efectivamente, desaparecen las dificultades del objetivismo y del subjetivismo, se puede hacer la siguiente objeción. ¿Cuál es el criterio que permite universalizar? ¿Por qué ciertas conductas son universalizables y otras no lo son? Cuando una persona acepta que una conducta puede universalizarse es porque dicha conducta le resulta valiosa 
y, en consecuencia, el criterio de universalidad se remite a la ética de los valores.

Pero esta objeción puede superarse porque existe un criterio de universalización que no depende de ningún valor: el criterio de no arbitrariedad. Un comportamiento es universalizable cuando no es arbitrario. En este sentido el criterio de universalización se independiza del valor porque la arbitrariedad o la no arbitrariedad de una acción puede determinarse de manera objetiva. Desde luego, como sucede en todo análisis de conceptos, cuando se quiere determinar con precisión la extensión del concepto de no arbitrariedad, pueden presentarse casos dudosos. Pero, de manera general, se trata de un concepto fácilmente aplicable.

El concepto de no arbitrariedad, por otra parte, integra el complejo de notas constitutivas del concepto de racionalidad. Lo que es racional no puede ser arbitrario. Basta pensar en el conocimiento racional para darse cuenta de que puede ser cualquier cosa menos arbitrario. La verdad no puede imponerse, sólo puede llegarse a ella mediante un proceso que no depende del arbitrio individual. Cuando se pasa del conocimiento a la acción la no arbitrariedad significa que se puede llegar al consenso, consenso que constituye la universalidad.

Sería demasiado largo entrar en un análisis detallado del concepto de no arbitrariedad. Una persona se comporta arbitrariamente frente a otras cuando intenta imponerles una conducta que ellas no han elegido y cuando ellas no intentan imponerle a dicha persona ninguna conducta. ${ }^{9}$

Vemos, así, que el criterio de no arbitrariedad permite saber cuándo un comportamiento es univerzalizable sin presuponer ninguna ética material de valores. En último término el rechazo de la acción arbitraria se debe a que ninguna persona puede aceptar ser tratada como instrumento por otra. No se trata aquí de jerarquía de valores sino de un rasgo constitutivo de toda persona.

Las consideraciones que anteceden nos permiten decir lo siguiente sobre la fundamentación racional de la ética. Una conducta es éticamente admisible si el fin que persigue es racional. Un fin es racional si la conducta que se requiere para realizarlo es universalizable. Una conducta es universalizable si es no arbitraria.

9 La casuística puede presentar sutiles y difíciles problemas cuando se trata de aplicar un concepto a los objetos que caen bajo su extensión. Por ejemplo, una persona que convence a otra porque es mucho más inteligente que ella y tiene mucho mayor cultura, Lestá procediendo arbitrariamente hacia ella? No es posible dar una respuesta tajante pero creemos, sin embargo, que sí está procediendo de manera arbitraria porque la está engañando. A sabiendas está influyendo en su conducta para desviarlo de los fines que habría elegido si no hubiera sido por su intervención. Esta situación muestra que los conceptos de arbitrariedad y no arbitrariedad, que en la mayoría de los casos son fácilmente aplicables, tienen, sin embargo, extensiones difusas. Pero esta dificultad en nada afecta el planteamiento de que una acción arbitraria no es universalizable y, en consecuencia, no es éticamente aceptable. 
Autobjeciones e intento de respuestas

Creemos que los desarrollos que anteceden muestran con claridad suficiente que el criterio de racionalidad, según el cual la aceptabilidad ética de un comportamiento depende de la posibilidad de universalizarlo, es superior a los criterios axiológicos. El criterio puede, también, aplicarse a los valores con mucho mayor precisión que cuando se considera que son los mismos valores los que constituyen el fundamento de la moralidad.

Pero debe reconocerse que no hay sistema ético que sea totalmente inmune a las objeciones y que pueda aplicarse de manera precisa en todos los casos. Por eso creemos conveniente señalar algunas de las dificultades que se presentan cuando se adopta el criterio de racionalidad como fundamento de la ética. El' hecho de plantearlas y de intentar resolverlas permitirá aclarar nuestro propio pensamiento y será útil para mostrar hasta dónde nuestros puntos de vista pueden enfrentarse a la crítica.

Una primera objeción que puede hacerse al criterio de racionalidad es que el hecho de que ciertos comportamientos nos parezcan universalizables y otros no, se debe a que los primeros constituyen una realización de ciertos valores típicos de la civilización occidental y los segundos constituyen una violación de valores que son, asimismo; típicamente occidentales. De manera que el criterio de universalidad sólo se puede aplicar en la cultura occidental.

No puede negarse que el criterio de racionalidad es típicamente occidental. El esfuerzo por fundar el conocimiento y la ética sobre la razón sin recurrir a otros medios es lo que caracteriza el espíritu moderno que, proveniendo de un largo proceso evolutivo durante la Edad Media, se manifiesta con mayor plenitud en el Renacimiento y culmina en los siglos subsiguientes. El intento por fundamentar la ética sobre bases estrictamente racionales es una de las más notables manifestaciones del espíritu moderno. No cabe duda, por eso, que "el criterio de racionalidad" es una de las maneras típicas por medio de las cuales el hombre de Occidente fundamenta su ética.

En este sentido debe reconocerse que en otras culturas y en las diferentes etapas de la propia civilización occidental ha habido y hay todavía otras maneras de fundamentar la ética. Pero lo que debemos preguntarnos es si el principio de universalidad sólo es aplicable en la cultura occidental o si puede aplicarse, también, en otras culturas. Para ello debemos aclarar aún más qué significa que un comportamiento sea universalizable.

Una nota esencial es que la universabilidad supone una relación de simetría entre las conductas de los miembros de la comunidad. La conducta de $a$ es universalizable cuando todos los demás sujetos de la comunidad pueden adoptarla. Por eso, si $a$ actúa de tal manera en relación con $b, b$ debe poder actuar de la misma manera sobre $a$. Si $a$ no acepta esta reciprocidad, entonces su acción no es universalizable. 
El principio de universalidad establece potencialmente una relación entre todos los miembros de la comunidad. El hecho de que $a$ asuma una conducta determinada no significa que, de hecho, todos los miembros de la comunidad asuman la misma conducta hacia él, pero sí que puedan asumirla y que él debe aceptarla. Si no existe esta posibilidad, el principio no puede aplicarse.

Ahora bien, no deja de ser notable que muchos de los comportamientos y los valores que, de acuerdo con los estándares de la civilización occidental, son universalizables lo sean también en las demás culturas. La lealtad, la generosidad, el heroísmo, etc., son universalizables en las más diversas civilizaciones y esto muestra que el criterio de racionalidad, aunque típico de Occidente, puede aplicarse fuera de su ámbito. Esto no significa, por cierto, que las culturas en las cuales se puede aplicar este criterio tuvieran conciencia del principio de universalidad, pero sí muestra que en el fondo de toda ética está latente el principio, latencia que se ha transformado en explicitud en la civilización occidental.

Desde luego, esta posibilidad de trascender sus propios límites sólo se presenta en relación con determinados valores y conductas, no con todos. Pero este hecho muestra el poder del criterio de racionalidad. Se trata de un criterio que nace en la civilización occidental (por lo menos en su versión moderna pues los griegos, aunque intentaron fundamentar la ética racionalmente, no llegaron a ver con claridad el criterio que se puede aplicar, de manera parcial pero significativa, en otras civilizaciones). Pero esto no significa que el criterio de universalidad, para aplicarse, presupone necesariamente la aceptación de valores occidentales. Puede objetarse que esta posibilidad de aplicación se debe a que se trata de los mismos valores en las diferentes civilizaciones. Pero puede pensarse lo contrario: que la posibilidad de universalizar ciertas conductas, en las diferentes sociedades, es lo que hace que dichas conductas sean consideradas valiosas.

De manera general puede decirse lo siguiente. El criterio de racionalidad es una expresión fundamental de la cultura de Occidente y, como tal, no puede considerarse de manera aislada. Su aplicación a la ética no es sino el resultado del ideal de racionalidad que caracteriza la civilización occidental. ${ }^{10} \mathrm{El}$ hombre de Occidente considera que su razón debe ofrecerle los criterios necesarios para orientarse en el mundo. Esta orientación es teórica y práctica. En el nivel teórico su razón le permite fundamentar el conocimiento mediante principios de aceptación universal; en el nivel práctico le permite fundamentar la ética mediante el principio de universalidad. Ya hemos visto que, en este caso, la razón sólo nos puede ofrecer un criterio negativo, pero permite orientarse con eficacia en el plano de la ética.

10 Sobre este punto véase Miró Quesada, "Hombre, naturaleza, historia. El problema de una fundamentación racional de la ética", en David Sobrevilla (comp.), El derecho, la política y la ética, Siglo XXI/UNAM, México, 1991, pp. 97-137. 
No cabe, pues, duda: el intento de fundamentar racionalmente la ética es típico de la ética de Occidente. Pero es una ética que rebasa los límites de Occidente y puede aplicarse, en buena proporción, a otras civilizaciones. Se puede aplicar en el sentido de que los miembros de estas civilizaciones aceptarían que ciertos comportamientos pudieran universalizarse.

Otra objeción que puede hacerse al principio de universalidad es la siguiente. En una civilización en la que existen castas, todos están de acuerdo en que existan, de manera que conforme al principio de universalidad, la existencia de castas debería ser considerada éticamente aceptable por los occidentales. Algo parecido sucede con el fundamentalismo islámico: en el Irán, por ejemplo, todos los hombres y las mujeres están de acuerdo en que las mujeres deben obedecer a los hombres, tienen que vestirse de cierta manera, no pueden tener cargos públicos, etc. La desigualdad está, así, universalizada.

Esta objeción parece fuerte, pero si se tiene en cuenta que la aplicación del principio de universalidad supone una relación de simetría entre las conductas de los miembros de la comunidad, vemos que no puede mantenerse. Es cierto que los hombres y las mujeres están de acuerdo en que las últimas estén sometidas a los primeros; es cierto también que en la India, en un pasado cercano, todos estaban de acuerdo en que la existencia de las castas era justa e incluso los parias aceptaban su condición. Pero si se comprende que la universalidad exige reciprocidad (simetría), entonces los sistemas considerados no son aceptables de acuerdo con dicho criterio. Para que una conducta sea éticamente aceptable debe ser universalizable, pero es evidente que los hombres, en la cultura fundamentalista islámica, no aceptarían que las mujeres mandasen y ellos obedeciesen. Lo mismo sucede con las castas. Ningún miembro de las castas superiores aceptaría asumir la condición de paria.

La respuesta es, por eso, que cuando en una sociedad hay grupos opresores y grupos oprimidos y aunque por razones religiosas o metafísicas los oprimidos estén de acuerdo con su situación, los comportamientos existentes no son universalizables porque los grupos opresores no están dispuestos a comportarse como los oprimidos. La aceptación de su condición por los oprimidos permite que en la comunidad exista una ética, pero de acuerdo con el principio de universalidad esta ética es inaceptable para el occidental.

Una tercera objeción es que el principio de universalidad es puramente teórico pues, en la práctica, nunca puede lograrse el consenso de toda la comunidad. Pero esta objeción parte de un desconocimiento del verdadero significado del principio de universalidad. El principio de universalidad no consiste en que una conducta sea asumida, efectivamente, por toda la comunidad, sino que dicha conducta pueda ser asumida por todos sus miembros. El hecho de que uno o más miembros de la comunidad se nieguen a asumirla no significa que no puedan asumirla. 
Como hemos visto, el criterio que permite saber cuándo una conducta es universalizable es el criterio de no arbitrariedad. El hecho de que una conducta determinada no sea aceptada por algunos elementos de la comunidad no significa que dicha conducta no sea universalizable pues, en caso de que no sea arbitraria, puede ser aceptada por todos. Y, por el contrario, quienes rechazan tal conducta proceden arbitrariamente. Supongamos que se trata del valor de la lealtad. El hecho de que $a$ se comporte lealmente hacia $b$ significa que $a$ no puede ser arbitrario con $b$ pues no tratará de impedir que $b$ realice sus fines. $Y$, recíprocamente, sucederá lo mismo si $b$ se comporta lealmente hacia $a$. Debido a la no arbitrariedad que caracteriza el comportamiento leal recíproco, la conducta leal puede universalizarse. Pero supongamos que a rechaza el comportamiento leal y decide comportarse deslealmente hacia sus semejantes. Para ser desleal deberá traicionarlos y, de una manera u otra, impedirá que realicen sus fines sin que ellos intenten impedir que él realice los suyos. Si su conducta es arbitraria no podrá universalizarse y no podrá, en consecuencia, ser considerada ética.

Vemos, así, que el principio de universalidad no significa que para que un comportamiento sea considerado ético todos los miembros de la comunidad deban asumirlo. Si así fuera sería imposible que existiera la ética (cualquiera que ella fuese) pues, en la realidad de la vida social, nunca se logra una completa coincidencia de todas las conductas. El criterio de la eticidad es que los comportamientos, para ser considerados éticos, deben ser universalizables. Y para saber si son universalizables, hay que saber si todos los miembros de la comunidad pueden asumirlos sin que se produzcan arbitrariedades como resultado de la asunción. El criterio de la no arbitrariedad permite distinguir entre lo que es universalizable y lo que no lo es porque lo que menos acepta una persona es que los demás se comporten arbitrariamente hacia ella. La no arbitrariedad es la condición de la aceptabilidad general y, en consecuencia, de la eticidad del comportamiento. 


\section{BIBLIOGRAFÍA}

Ayer, Fred Jules, Language, Tiuth and Logic, Oxford University Press, Londres, 1936. -, Freedom and Morality and other essays, Oxford University Press, 1984. Ferrater Mora, José, Diccionario de Filosofía, Alianza Editorial, 1982.

Frondizi, Risieri, Introducción a los problemas fundamentales del hombre, Fondo de Cultura Económica, México, Buenos Aires, 1977.

Garzón Valdés, Ernesto, Derecho y filosofía, prólogo de Garzón Valdés, Editorial Alfa, Caracas, 1985.

Miró Quesada C., Francisco, Ensayos de filosofía del derecho, Instituto de Investigaciones Filosóficas, Lima, 1986.

- Hombre, naturaleza, historia, Actas del congreso internacional de filosofía, Universidad Nacional de Córdoba, Argentina, 1987.

-, Ensayo de una fundamentación racional de la ética, Instituto de Investigaciones Filosóficas (circulación interna), Universidad de Lima, Perú, 1994.

Nietzsche, Friedrich, The Will to Power, Vintage Books, Nueva York, 1968.

- Jenseits von Gut und Böse, Carl Hanser Verlag, München, 1973a.

-, Die frölische Wissenschaft, Carl Hanser Verlag, München, 1973b.

—- Der Antichrist, Carl Hanser Verlag, München, 1973c.

Perry, Ralph Barton, Realism in retrospect, George Allen \& Unwin LTD, Nueva York; The Macmillan Company, Nueva York, 1926.

Russell, Bertrand, Perspectivas de la civilización industrial, Aguilar, Madrid, Buenos Aires, México, 1949.

—-, Etica e politica na Sociedade Humana, Zahar Editores, Río de Janeiro, 1977.

- Summa contra Gentiles, Biblioteca de Autores Cristianos, Madrid, 1968.

Williams, Edward O., Sociobiología. La nueva síntesis, Ediciones Omega, S.A., Barcelona, 1980a.

—, Sobre la naturaleza humana, Fondo de Cultura Económica, México, $1980 \mathrm{~b}$. 